\title{
تصميم وتنفيذ برناهمج في حسابات إنتاج الغزل
}

إعداد

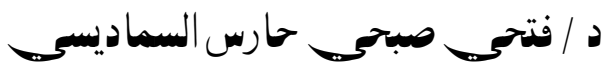

مدرس بقسم الغزل والنسيج والتريكو

كلية الفنون التطبيقية - جامعة دمياط

مجلة بحوث التربية النوعية ـ جامعة المنصورة

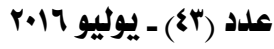




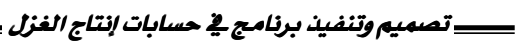




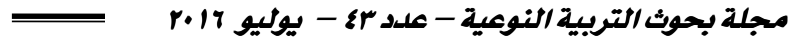

\section{تصميم وتنفيذ برناهج في حسابات إنتاج الغزل}

إعداد

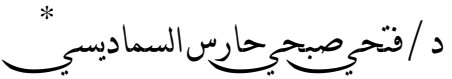

\section{هذص البمث}

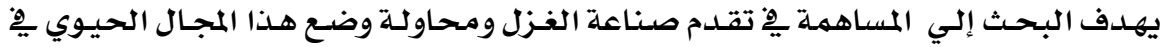

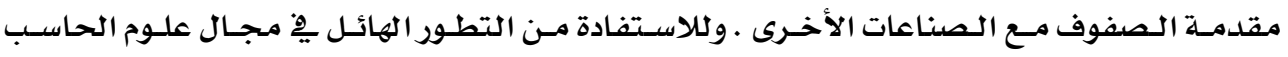

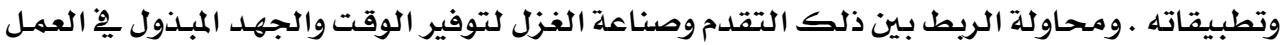

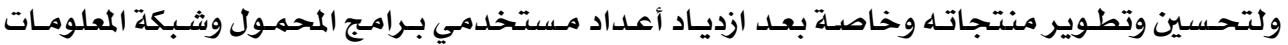

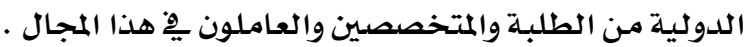

ولافتقار المكتبة العربية من مثل هذه النوعية من الأبحاث فهدف البحث هو إثرائها بما هو جديد .

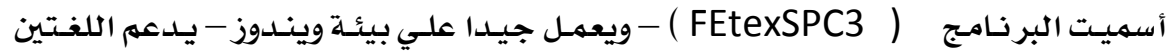
العربية والانجليزية أثناء التشغيل صغيرة مساحة تخزينه على القرص الصلب .

\section{ومن خلال هذا البحث والبرنامـج التابع له يمكننا الآتي :}

ا - عمـل تطبيقـات للعلاقـة الرياضـية بـين النهـرة الانجليزيـة - ووزن يـاردة مـن الشـريط بـالجرام.

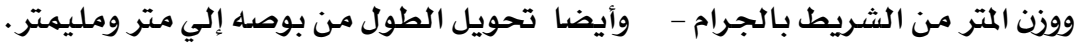

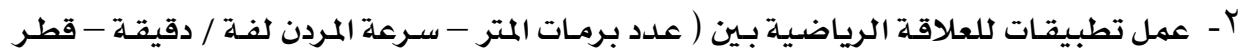

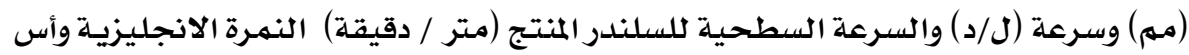

$$
\begin{aligned}
& \text { البرم . }
\end{aligned}
$$

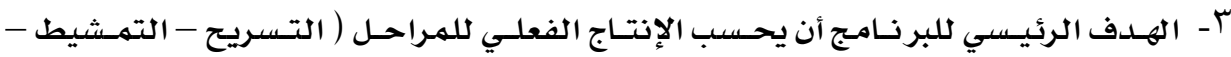

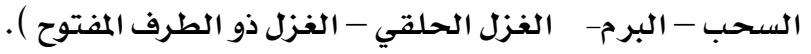

يِادخال بيانات مثل : علدد الماكينات -كفاءة التشغيل - عدد المرادن أو الـرؤوس - السرعة

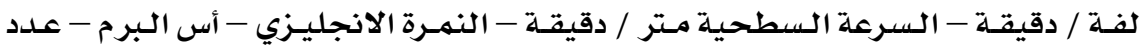

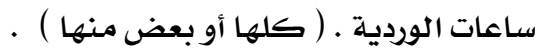

$$
\text { وذلك للحصول منها علي الآتي : }
$$

أ- إنتاجية الماكينة كجم / ساعة ولكل وردية ولكل يوم · ل

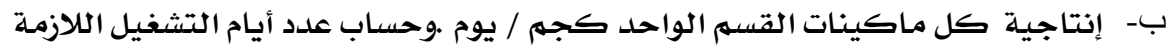

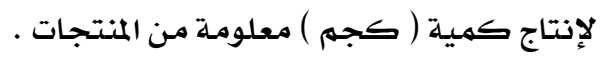

* مدرس بقسم الغزل والنسيج والتريكو كلية الفنون التطبيقية - جامعة دمياط 


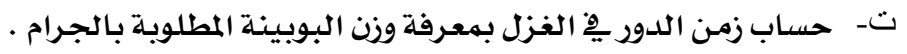

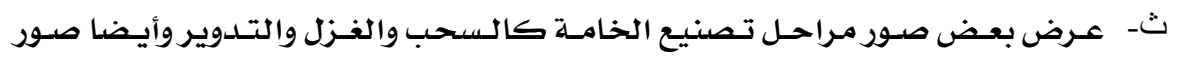
البوبينة والكونة .....

الاقدمهة :

تعد صناعة الغزل من الصناعات الهامة التي تتعامل مـع الألياف والشعيرات بطرق مختلفـة

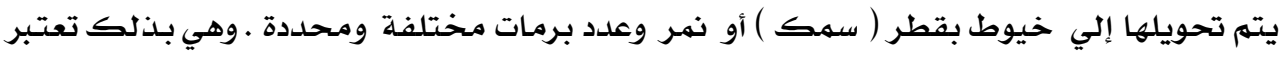

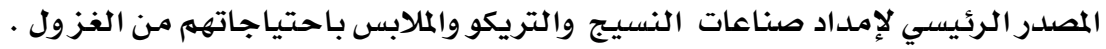
ومما هو معروف أن صناعة الغزل تعتمد علي خطوط إنتاج متكاملة لكثرة وتشعب مراحلها

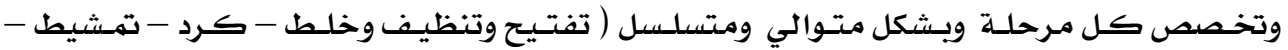

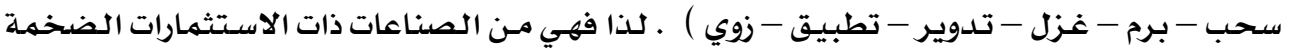

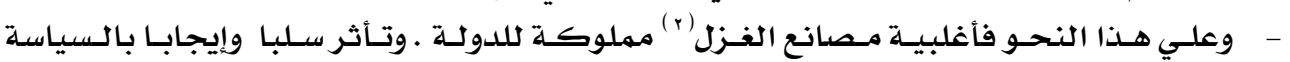
الداخلية للدولة .

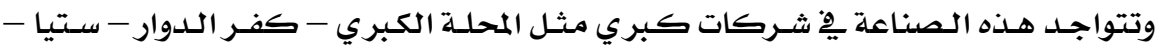

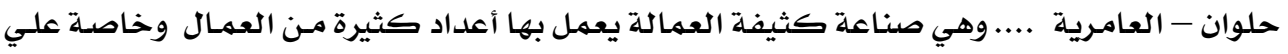

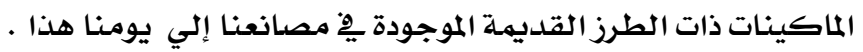

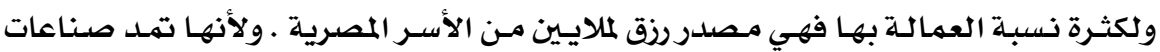

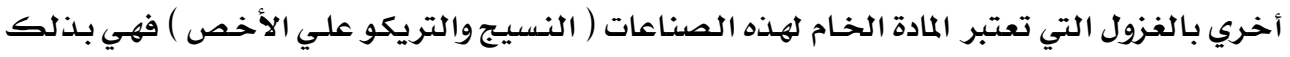

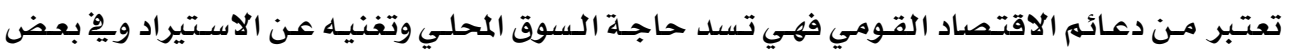

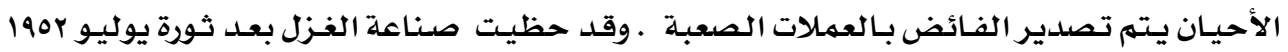

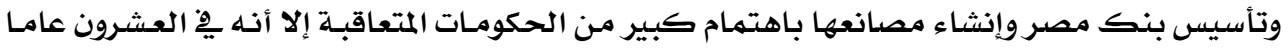

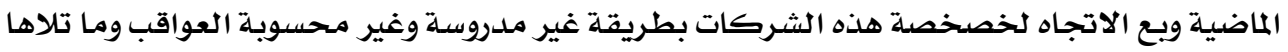

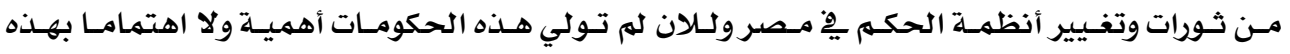

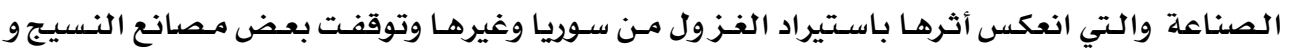

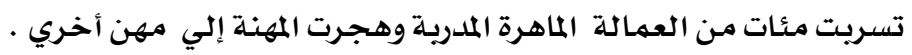

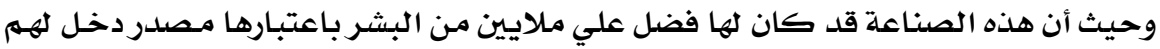

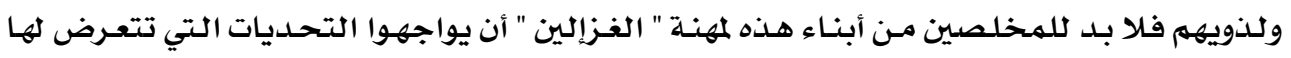

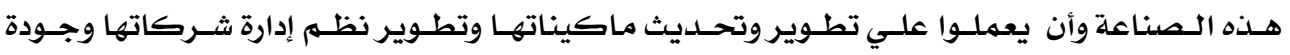

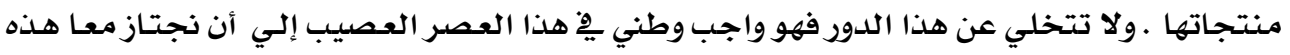

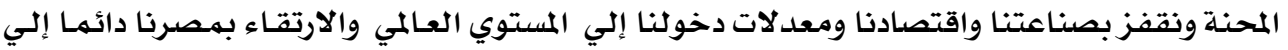




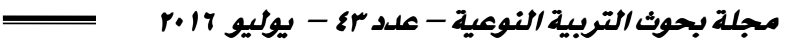

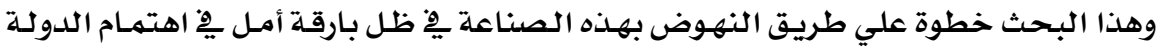

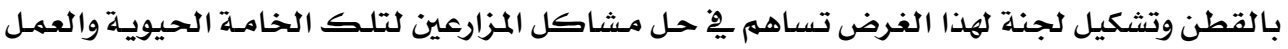

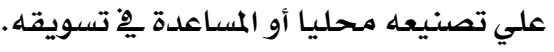

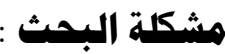

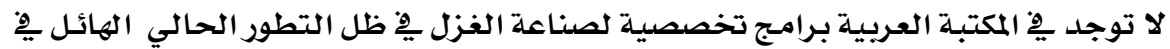

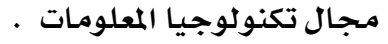

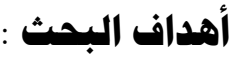

ا.تبسيط العلوم المعرفية النسجية لإمكانية تداولها وانتشارها بها يحقق المنفعة العامـة .

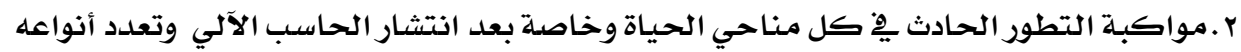

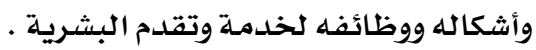

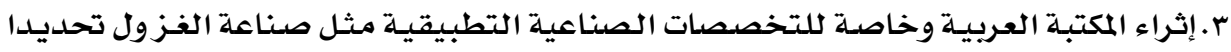

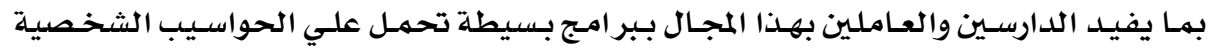
وتستعمل بسهولة ويسر

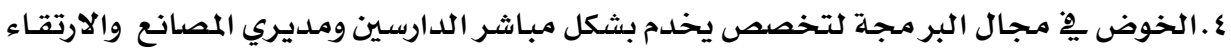

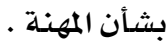

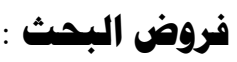
ا ـ توجــ علاقـات رياضـية بـين كـل مـن : عـد د برمـات الوحسدة وعـدد لفــات المـردن وقطـر وسـرعة

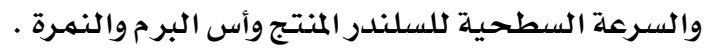

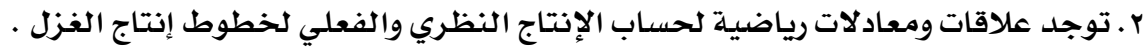

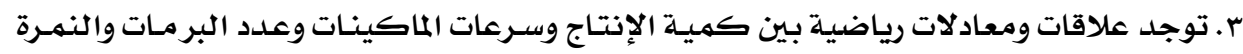

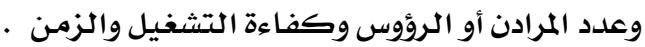

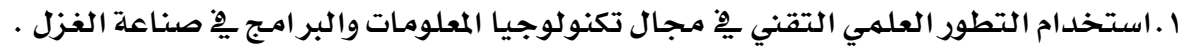

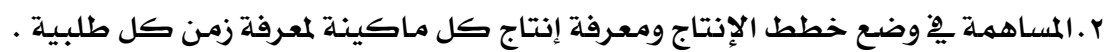

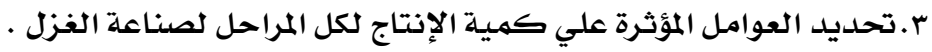
هدود البمث :

• ِِّ التحضيرات ( التسريـح - التمشيط - السحب - البرم ) وِِّ مـراحل الغـزل (الحلقي والغـزل ذو الطرف المفتوح) .

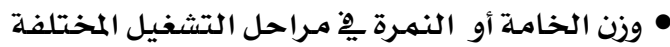

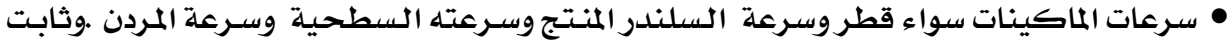

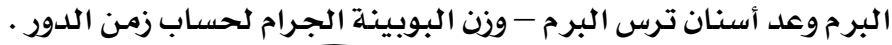


الغـزل spinning - combing - التسريح ( الكرد ) carding - التمشيط البرم

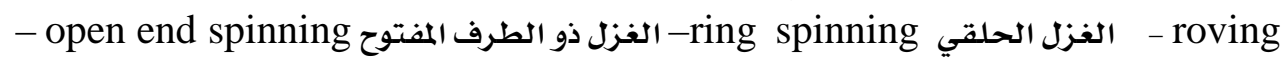

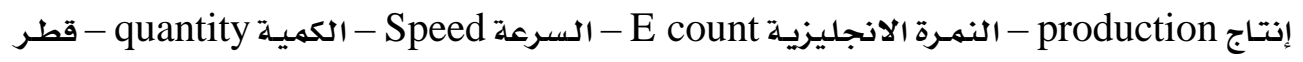
delivery roller surface عوادم - السرعة السطحية للسلندر المنتج - Waste - diameter

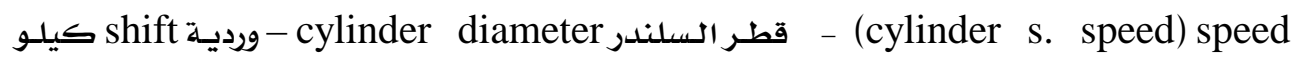

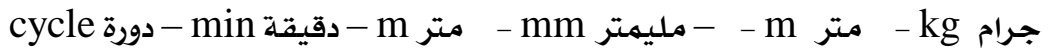

\section{همتويات البرنامهج :}

FEtexSPC3 : الاسه المختصر المقترح للبر نامـج

\section{Forms يحتوي البرنامج علي ع أجزاء}

\section{الصفحة الأولي للبرنامج : الصنوي}

كما يوضحها شكل رقم ( 1 ) الواجهة الرئيسية للبر نامج تحتوي علي :

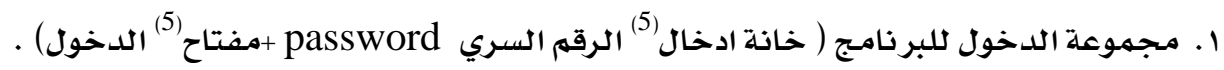

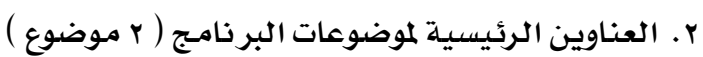

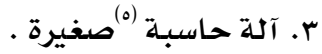

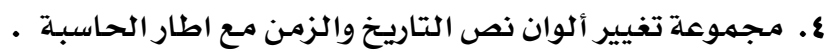

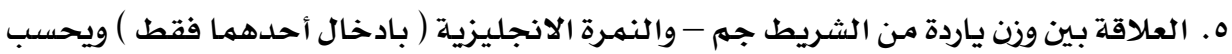

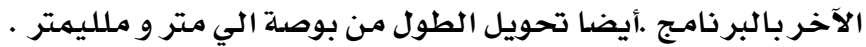

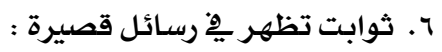

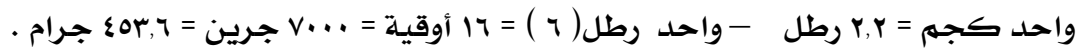

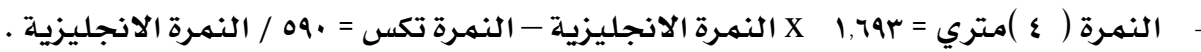


زمـن الـدور( 1 ) النظـري ِِّ الغـزل = طـول المبروم علـي البكـرة ( مـتر ) / السـرعة السطحية

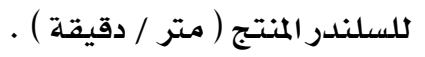

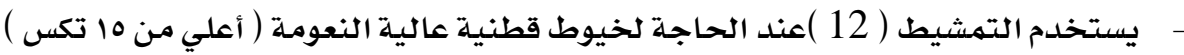

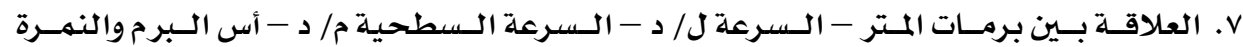

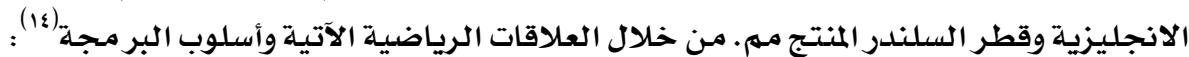

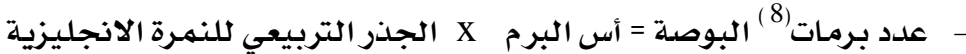

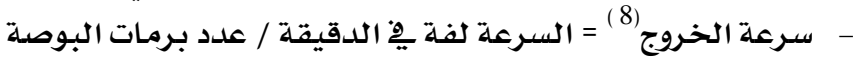

- عدد برمات المتر = سرعة المردن ( ل/ د) / السرعة السطحية للسلندر المنتج ( م/ د د)

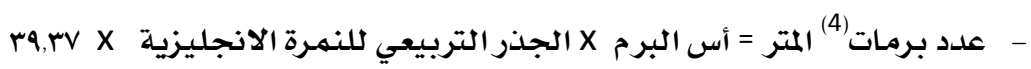

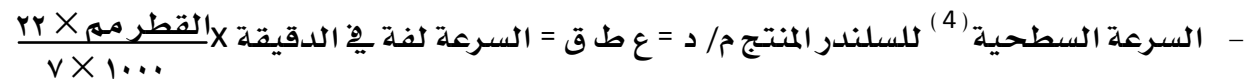

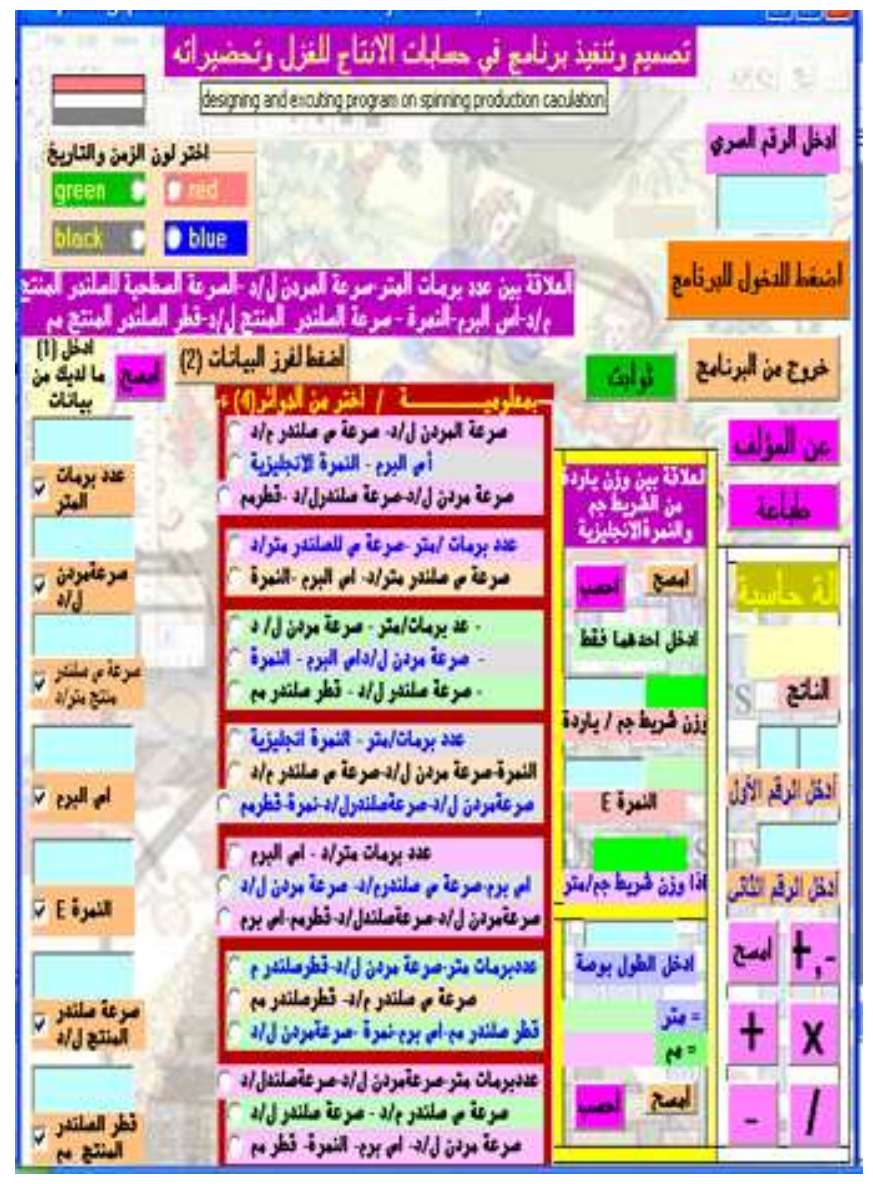

$$
\text { شكل رقم ( } 1 \text { ) يوضح الواجهة الرسومية للبرنامج }
$$




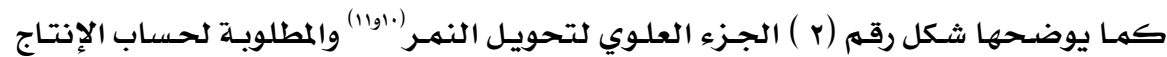

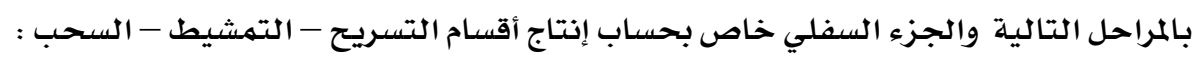

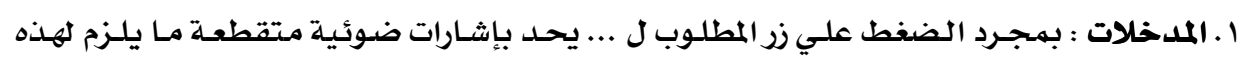

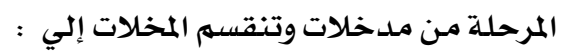

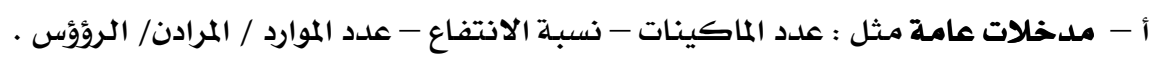

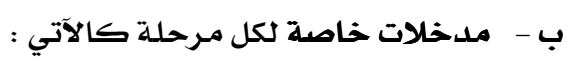

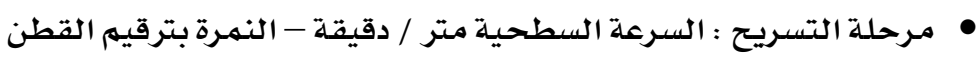

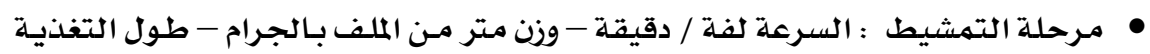

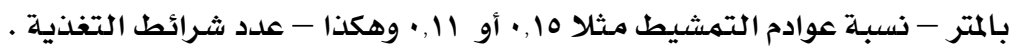

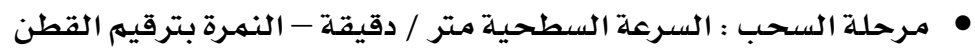

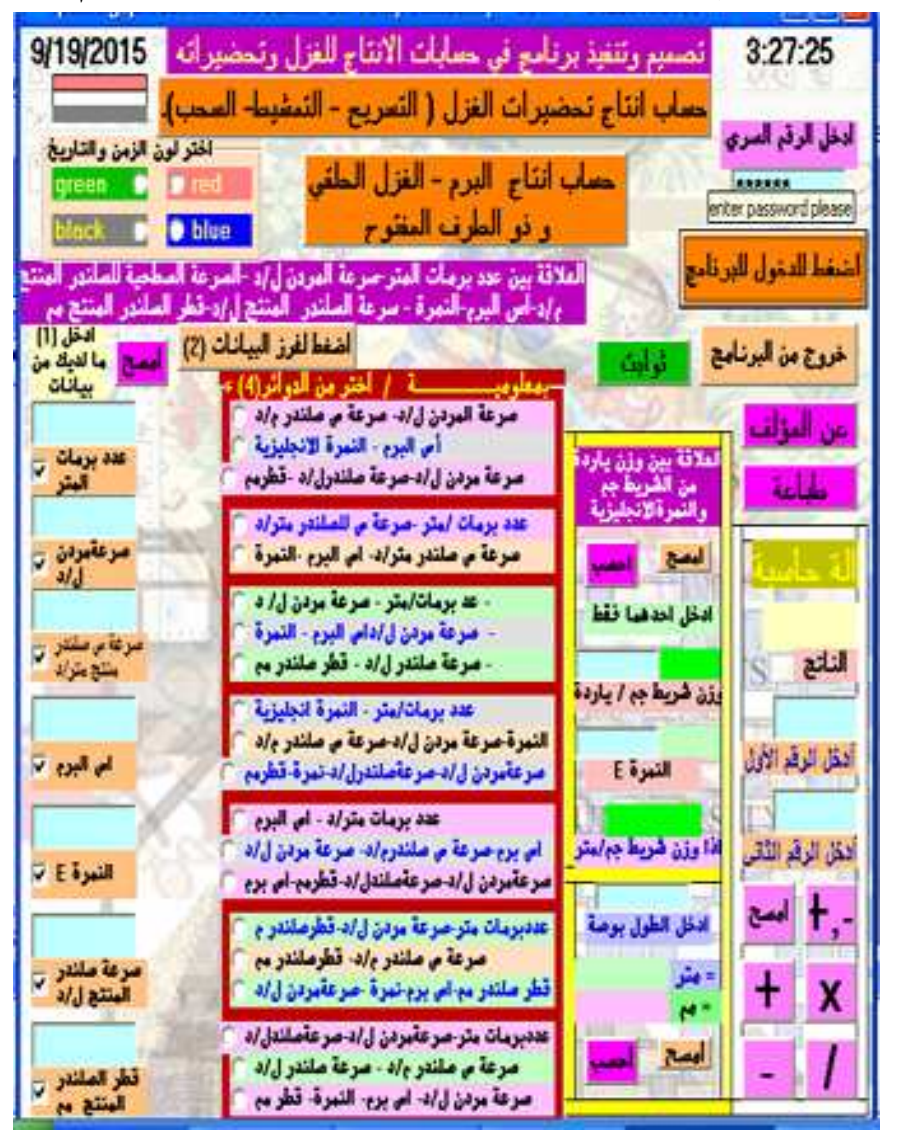

شكل رقم ( r ) يوضح الواجهة الرسومية للبرنامج بعد إدخال الرقم السري 


$$
\begin{aligned}
& \text { r- المخرجات : } \\
& \text { لجميع المراحل : } \\
& \text { • إنتاج الماكينة كجم / ساعة . }
\end{aligned}
$$

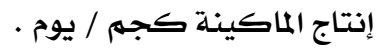

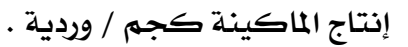

$$
\begin{aligned}
& \text { إنتاج القسه كجهم / وردية . }
\end{aligned}
$$

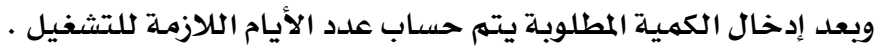

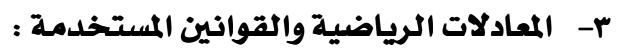

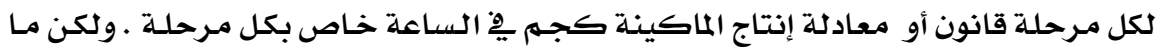

$$
\text { بعد ذلك ينطبق علي جميع المراحل وهي : }
$$

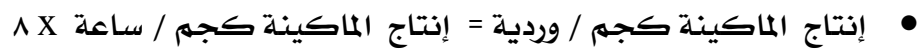

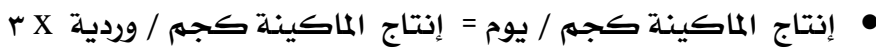

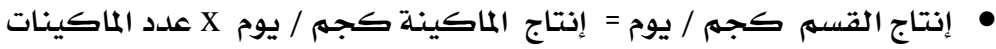

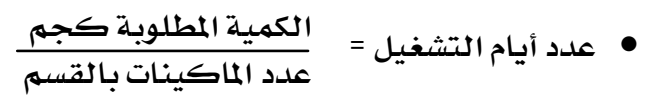

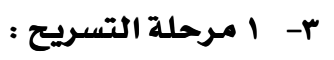

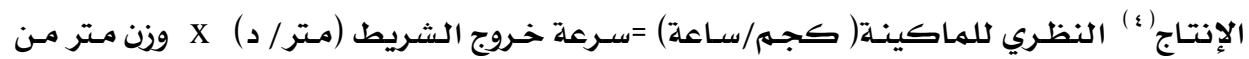

$$
\text { الشريط(جم) الانتاج) }
$$

الإنتاج الفعلي (ء) للماكينة( كجم/ساعة) = الإنتاج النظري ( كجم/ساعة) X نسبة الانتفاع

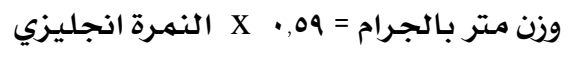

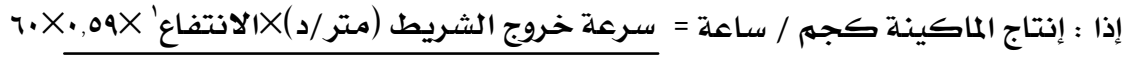

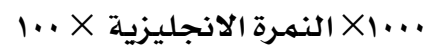

\section{r- r مرحلة التمشيط}

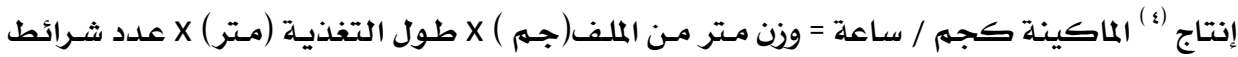

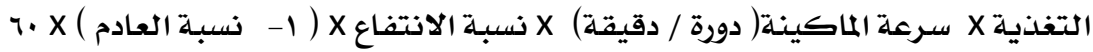

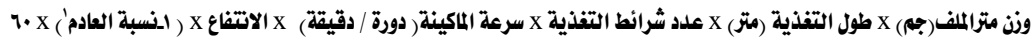

إذا :الإنتاج=

$1 \cdots \times 1 \ldots$

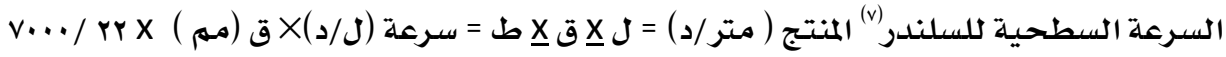




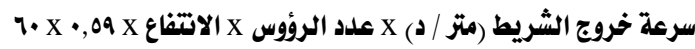
1... × النمـرة الانجليزية

اذا : إنتاج الماكينـة كجمم / سـاعة =

\section{• الصفحة الثالثة للبرنامج :}

$$
\begin{aligned}
& \text { خاصة بحساب إنتاج أقسام الغزل الحلقي والغزل ذو الطرف المفتوح } \\
& \text { تحتوي هذه الصفحة علي جزئين : هiئ } \\
& \text { الجزء الأول : مرحلة البرم : السرعة للهردن (لفة / دقيقة) - النمـرة بترقيهم القطن - أس البرم } \\
& \text { الجزء الثاني : خاص بحساب إنتاج الغزل الحلقي والروتور ذو الطرف المفتوح وبه : } \\
& \text { 1. المدخلات: }
\end{aligned}
$$

عدد الماكينات - نسبة الانتفاع - عدد المرادن- السرعة (لفة / دقيقة) - النهمرة بترقيم القطن

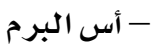

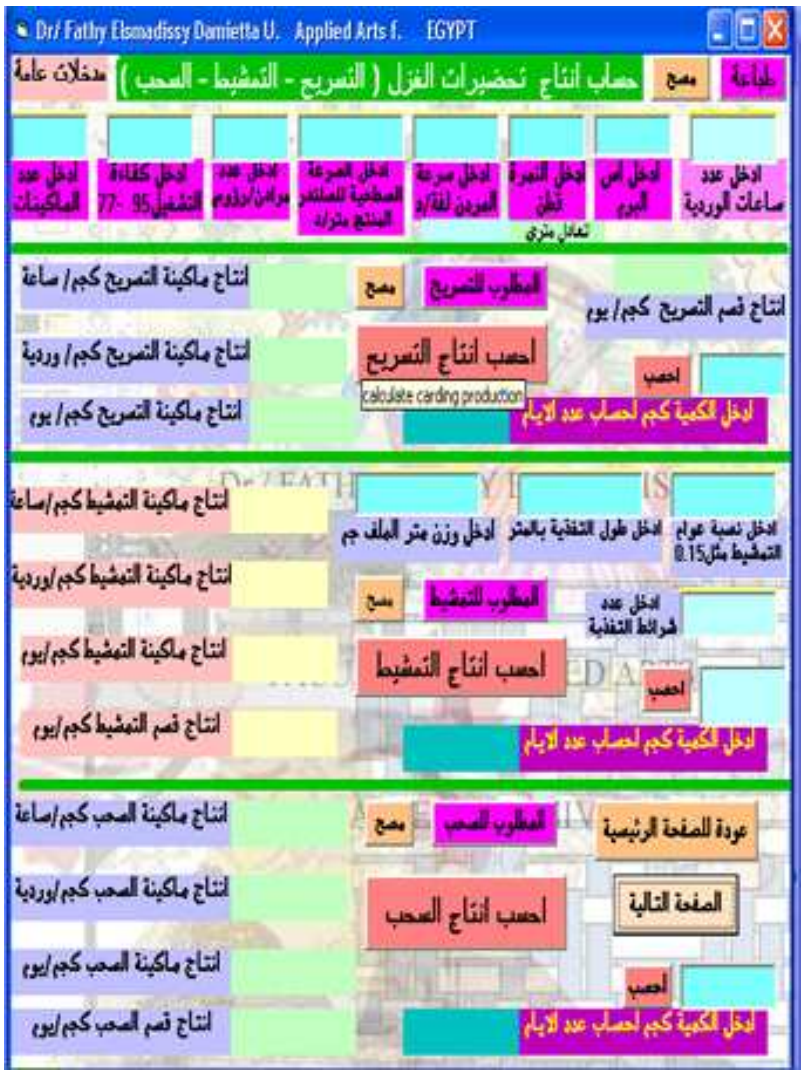

شكل رقم ( r ) يوضح برنامج حساب إنتاج مراحل ( التسريح - التمشيط - السحب ) 


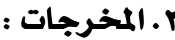

$$
\begin{aligned}
& \text { - إنتاج الماكينة كجم / ساعة + / يوم + / وردية . }
\end{aligned}
$$

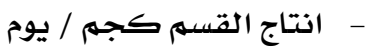

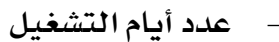

r. مستخلدما العلاقات الرياضية الآتية :

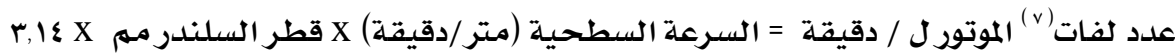

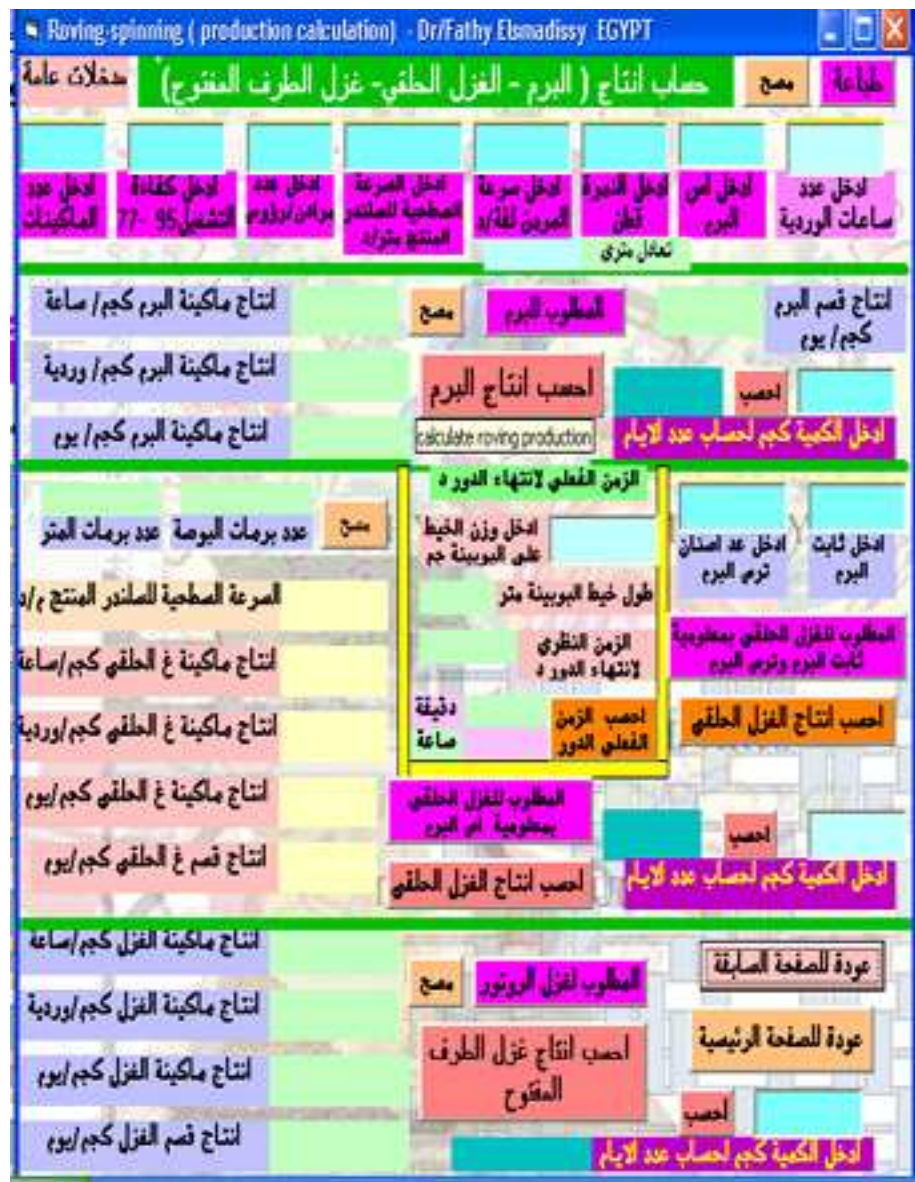

ثكل رقم ( ع ) يوضح برنامـج حساب إنتاج ماكينات الغزل ( الحلقي وذو الطرف الفتوح ) .

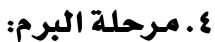

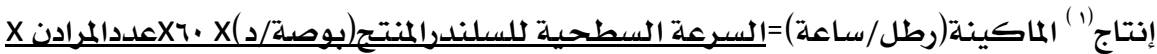
نسبـة الانتفاع

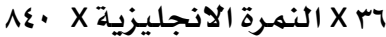


- سرعة خروج ( ) المبروم (متر / دقيقة) = سرعة المردن (لفة / دقيقة ) / عدد البرمات يِّ المتر

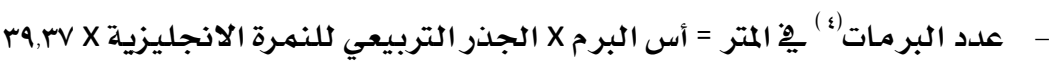

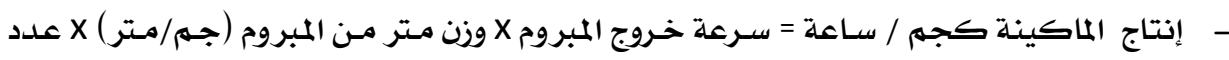

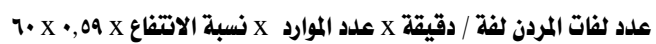

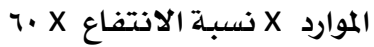
علد برمات المترx النمرة الانجليزية x ... إنتاج (rا ) الماكينـة كجمر / ساعة =

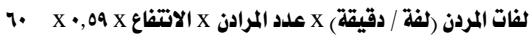

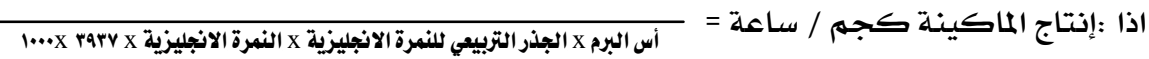

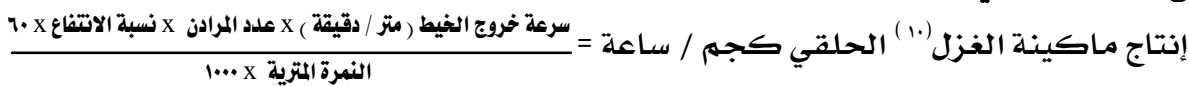
هـ الغزل الحلقي :

يهـن حسـابـه بعدة طرق منها :

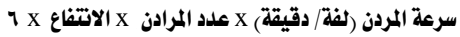

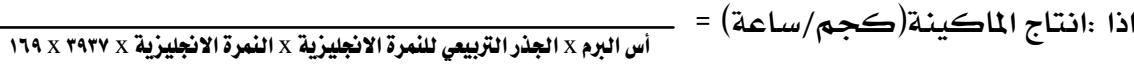

$$
\begin{aligned}
& \text { ب : إنتاج الغزل الحلقي بمعلومية ثابت البرم وترس البرم : } \\
& \text { حيث أن : عدد (r) برمات البوصسة = ثابت البرم / ترس البرم } \\
& \text { اذا عدد برمات المتر = ثابت البرم rV X,r / ترس البرم }
\end{aligned}
$$

بما ان عد برمات المتر = سرعة المردن (ل/د ) / السرعة السطحية للسلندر المتتج (متر/ دقيقة )

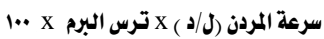
ثابت البرم Prry اذا السـرعة السطحية للسلندر المنتج (متر /دقيقة ) =

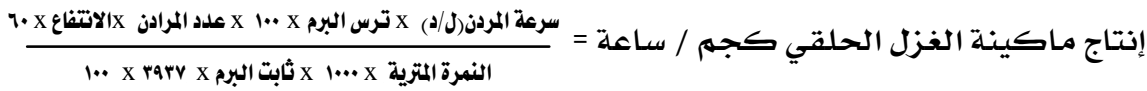

\section{ج - حساب زمن انتهاء دور الغزل بمعلومية وزن البوبينة (جم ) :}

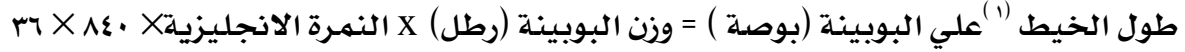
الزمن اللازم (1) لانتاج بوبينـة (دور) = طـول الخيط علسي البوبينـة (بوصسة) /سـرعة السلندرر المنتـج 


$$
\text { - اذا الطول بالمتر = النهمرة متري X الوزن بالجرام }
$$

- الزمن النظري (1) لانتهاء الدور = طول الخيط بالمتر/السرعة السطحية للسلندر المنتج (متر/دقيقة)

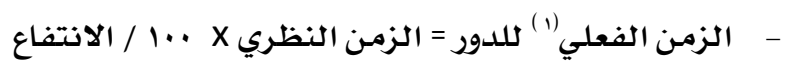

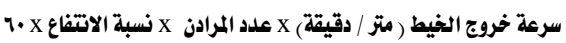

$$
\text { 7 ـ الغزل ذو الطرف المفتوح : }
$$

النهرة المترية X إنتاج الماكينة (؛ ( (كجمر / سلاعة)

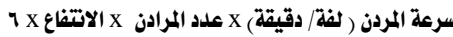

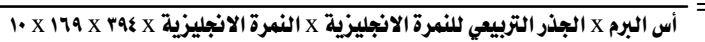

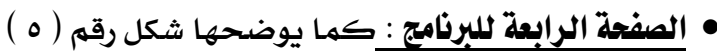

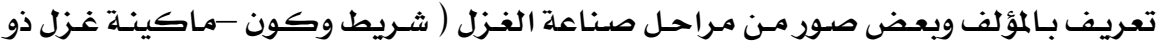

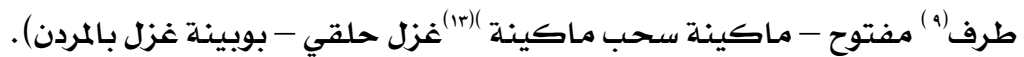

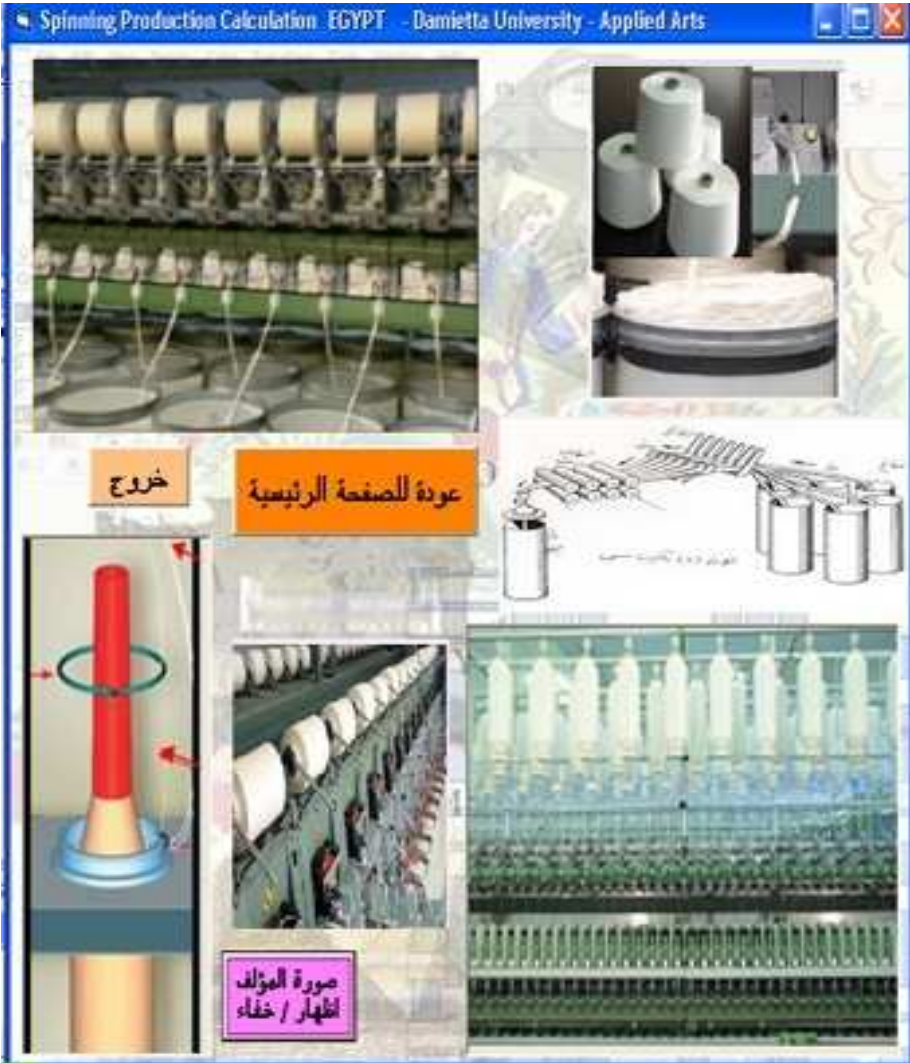

ثكل رقم ( ه ) يوضـح تعريف بالمؤلف وبعض صور من مراحل صناعة الغزل 


$$
\text { يمكن استخدام البرنامج المرفق بالبحث : }
$$

ا ـ يمكن بالبر نـامـج إيجـاد سـرعة مـردن الغـزل ( لفـة / دقيقـة) أو قطـر السلندر المنتجج( مللسيمتر )

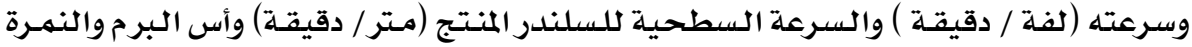

$$
\text { وعد برمهات المتر . }
$$

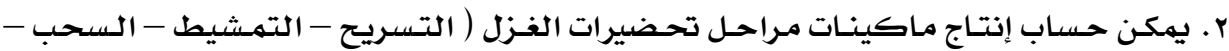

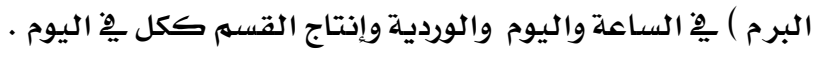

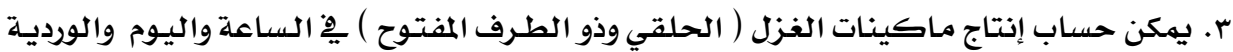

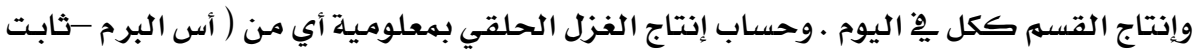

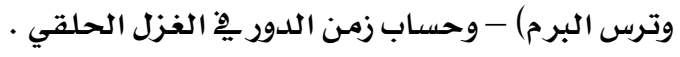

ع. يمكن حساب عدد الأيام اللازمة لتشغيل كمية معينة .

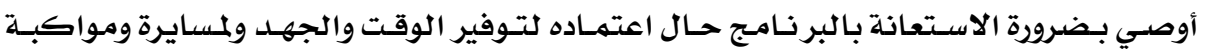

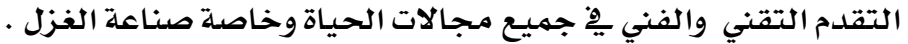

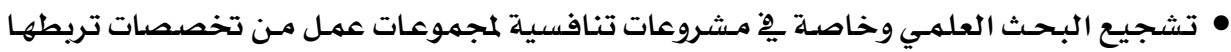

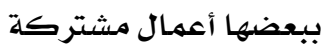

• الاهتمام بتدريس البر مججة ِِّ التخصصات العملية بالجامعات والمعاهد العليا .

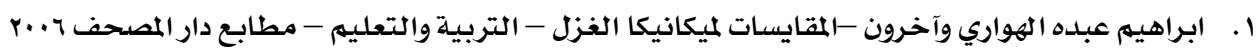

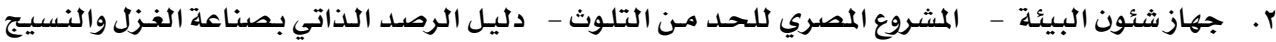

r r...r

r. سيد علي السيد - تكنولوجيا مـراحل الغزل - كلية الفنون التطبيقية - جامعة حلوان . ع. صلاح الدين صدابر - تكنولوجيا الغزل- صندوق دعم صناعة الغزل والمنسوجات - الاسكندريـة

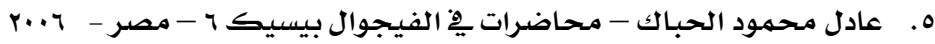

7. فتحي صبحسي حارس السماديسي - تصميهم وتنفيذ برنامـج للرياضة التطبيقية للنسيج - بحـث منشور -

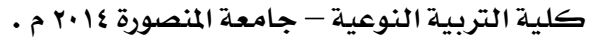

V. كاميليا محمد عبد الرحمن وآخرون -تخطيط وادارة إنتاج - نسيج r سنوات - وزارة التربيـة والتعليهم -

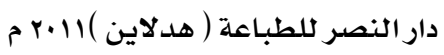

^. محمد أحمد سلطان - تكنولوجيا وحسـابات غزل القطن - مؤسسة المعارف للطباعة والنشر

9. محمد ياسـر - الغزل الروتور ذو الطرف المفتوح - سوريا . 


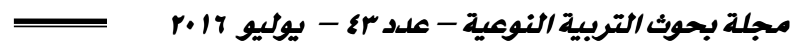

10. Bhavdip k.laldiya - different yarn count systems / conversion .Sarvajanik un.surat- India .

11. Henery Frowde and Hodder - Yarn counts and calculations -Thomas woodhouse-London.

12. S.gordon and y.l.hsieh - cotton science and technology -textile institute

13. S.m. hossen uzzal- production calculation of ring frame - monno fabrics ltd . mani kgonj

14. Nissan university-college of engineering - lectures in visual basic . 


\title{
Designing and Executing Program in Spinning Production Calculations
}

\section{FEtexSPC3}

\author{
Dr. (lec.) / Fathy Sobhy Haris Elsmadissy*
}

\section{Abstract}

This search aim to contribute in progressing on the Spinning industry and attempt to put this virtual field on the first line with another industries, thus to benefit from the massive development in computer sciences and its applications and to connect this progressing with the spinning industry to keep the time, effort in work and improve the products specially after increasing humans number which using mobile programs ,internet from students and who work in this field from the specialist people .

Because it's very lack to this type of this researches .

this search aims also to enrich the Arabic library with the newer .

I named this program (FEtexSPC3 ). It work well in windows, work in Arabic an English languages , little storage area on hard disk .

\section{From this research and its program we able to do the next :}

1-Show applications from math. Relation between E count, weight (gram) / 1 yard of sliver and get the sliver weight (gram $/ \mathrm{m})$. also convert length from inch to meter .

2- Show applications from math. Relation between((twists number/m spindle speed (cycle/min) - delivery cylinder surface speed $(\mathrm{m} / \mathrm{min})$ - cylinder diameter (mm) - cylinder speed (cycle/min) - E count, twist factor).

3-The main aim to calculate the actual production for (carding combing - drawing - roving - ring spinning - open end spinning ) in ring spinning by two methods (twist factor - twist gear teethes) by entering data such as : the many machines, efficiency, many spindles (heads), delivery speed $\mathrm{m} / \mathrm{min}$ - speed cycle / min - E count - twist

* Spinning, Weaving and Knitting Dept . Faculty of Applied Arts Damietta University 


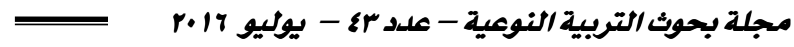

factor , shift many hours .(all or many of it) to get the production/ machine/h+ / shift + /day and production $\mathrm{kg}$ for all machines on department/day . also calculate the work days which needed to produce any quantity $(\mathrm{kg})$ from production .

4- calculate the end role time in ring spinning by using the required bobbin weight (gram) .

5- show some pictures about drawing, ring frame spinning, winding machine ,spindle ,bobbin, cones...

This search aim to development and progressing spinning industry . 